\title{
Will This Recession Undermine Diversity and Inclusion in Sports?
}

\author{
Camille O'Bryant \\ Cal Poly State University
}

I want to begin my remarks with a heartfelt thank you to Jay Coakley for inviting me to participate in this colloquium. It is indeed an honor and a privilege to be in the company of such outstanding scholars and professionals who are truly committed to and invested in promoting meaningful and enjoyable competitive sport experiences for college students. I also want to take a few moments to personally and professionally thank Richard Lapchick. I don't know if he remembers the first time that I met him. It was the summer of 1992. I was in Boston for a short visit to family when I went to see my uncle who was vice president for student affairs at Northeastern University at the time. My uncle, John O'Bryant, began his professional career as a physical education/health teacher and coach in the Boston Public Schools.

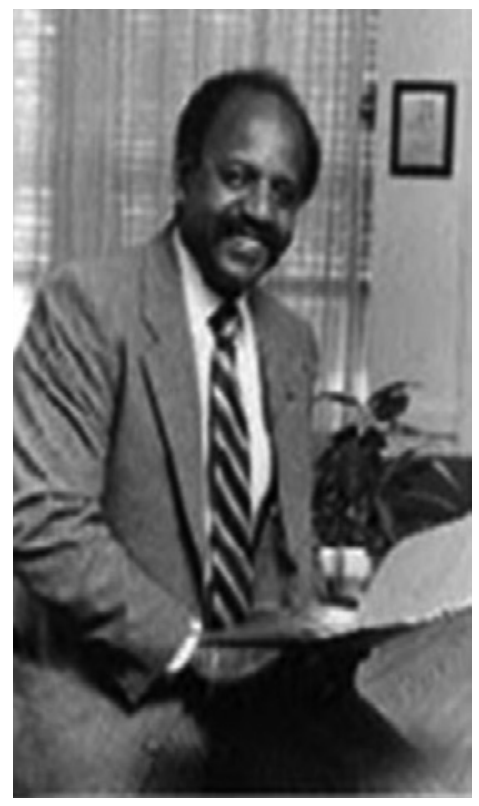

John D. O’Bryant () 1992 Vice President for Student Affairs, Northeastern University (www. northeastern.edu/aai/johndobryant.html) 
I had just finished my first year of graduate study in my doctoral program at Ohio State and my uncle thought I would like to meet Richard and tour the newly formed Center for the Study of Sport in Society at Northeastern University. This was very exciting to me because I had just researched and written a paper on the low numbers of African American women in leadership/coaching positions in sport and was curious to learn about the types of programs available. Needless to say I was very excited to learn more about the various programs and projects in the Center and extremely delighted to meet Richard Lapchick. He was probably one of the first white men I had met who truly demonstrated to me what a person can do to a) raise awareness about the gross inequities in sport-specifically professional and college sport - and b) how it truly takes a village of concerned people and their allies to facilitate social change in sport. Meeting with Dr. Lapchick at that time also provided me with a deeper understanding of a quote that is attributed to my uncle John- "If you are not here to serve the students, you are in the wrong place". That quote was the cornerstone to John O'Bryant's personal and professional code of ethics, and, I believe, it should also be the foundation upon which administrators and officials in organizations such as the NCAA build, nurture and sustain intercollegiate sports.

I also want to take a moment to publicly thank my mother, Joan O'Bryant. She was a dancer and played the bass drum in a high school drum and bugle corps. Although she was never involved in organized sport-as we know it today-she managed to help my siblings and me develop the belief and confidence that we could be and do anything we wanted. I'm actually glad that she wasn't the quintessential "little league parent" because I was allowed to develop my own sense of self and connection to sport with my peers on my high school and college teams.

\section{Who I Am}

As you can see from the program, my name is Camille O'Bryant. I was born and raised in Boston, MA during a time when the city was intensely segregated by race/ ethnicity - not to say that it still isn't. There truly were portions of the city that I would not venture into as an African American woman, and I daresay that there may have been White people who would not venture into sections of the city where

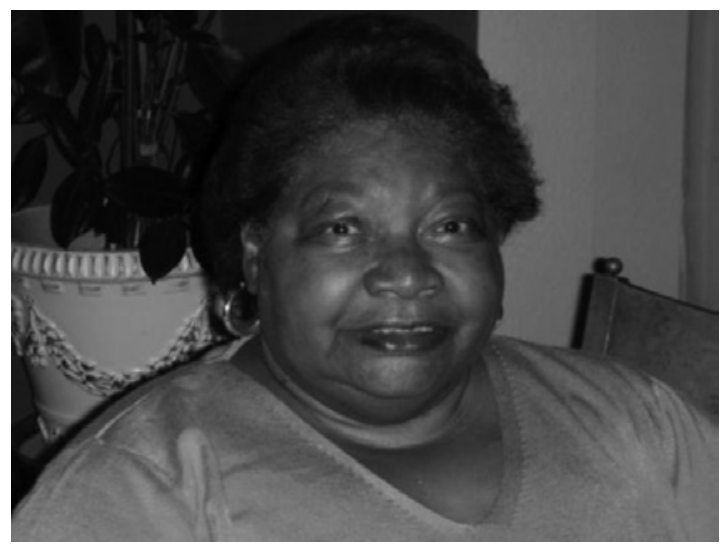

Joan O'Bryant (photo courtesy of Camille O'Bryant) 
I spent most of my time. The neighborhoods change as the years go by; but during my childhood, Roxbury was predominantly the home of African Americans or immigrants from the West Indies. My male cousins were members of the Roxbury Boys Club. They joined the swim team. Not long after they joined the swim team at the Roxbury Boys Club, the aquatics coordinator, Don Frye, asked swim team members to encourage their sisters to come and learn how to swim early Saturday mornings before the Boys Club opened-girls were not allowed to be members of the Boys Club at the time. Not long after this announcement, my sister, female cousins, and I started going to "girls swim". It wasn't much longer before girls were allowed to join the Boys Club-now called Boys and Girls Club-and we all were part of the swim team. Of course the admission of girls to the boys' clubs of Boston occurred not long after the passage of Title IX.

In the 1970s nearly every member of the swim team was Black/African American and a few were Puerto Rican. It was interesting to observe how other swim teams would respond to us when we showed up for swim meets. Although the girls were not allowed to be "official" members of the swim team in 1975-1976, it was refreshing for me to find some photos of the current Boys and Girls Swim Team from the 2008 nationals and see that girls and boys are still participating in age group swimming.

I won't go into details about the stereotypes related to black people and swimming; but I did want to give members of the audience this brief history of my introduction to organized competitive sport because right from the very start of my involvement in organized sport, I knew first hand that race/ethnicity and gender truly did matter in terms of who could or could not participate in sport. Actually as I look at these images of the young boys and girls involved in swimming, I wonder what, if anything, we know about them? Much of the research and writing about intercollegiate sport is focused on men's football, men's basketball and occasionally,

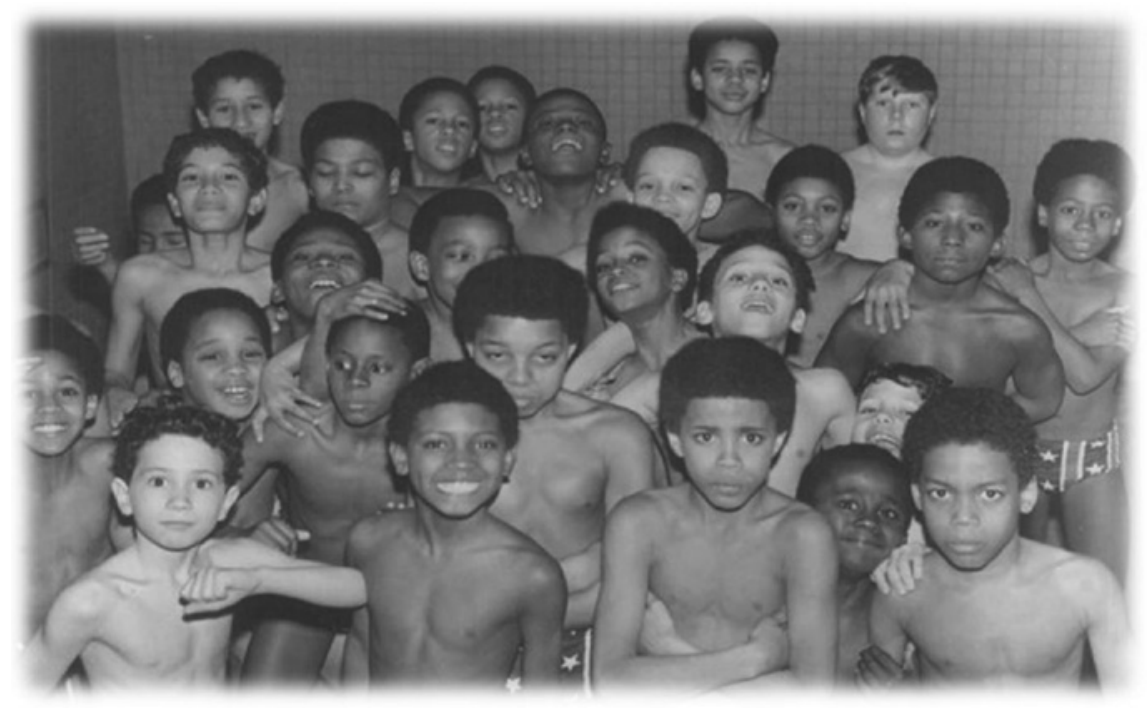

Roxbury Boys Club Swim Team (C) 1976 


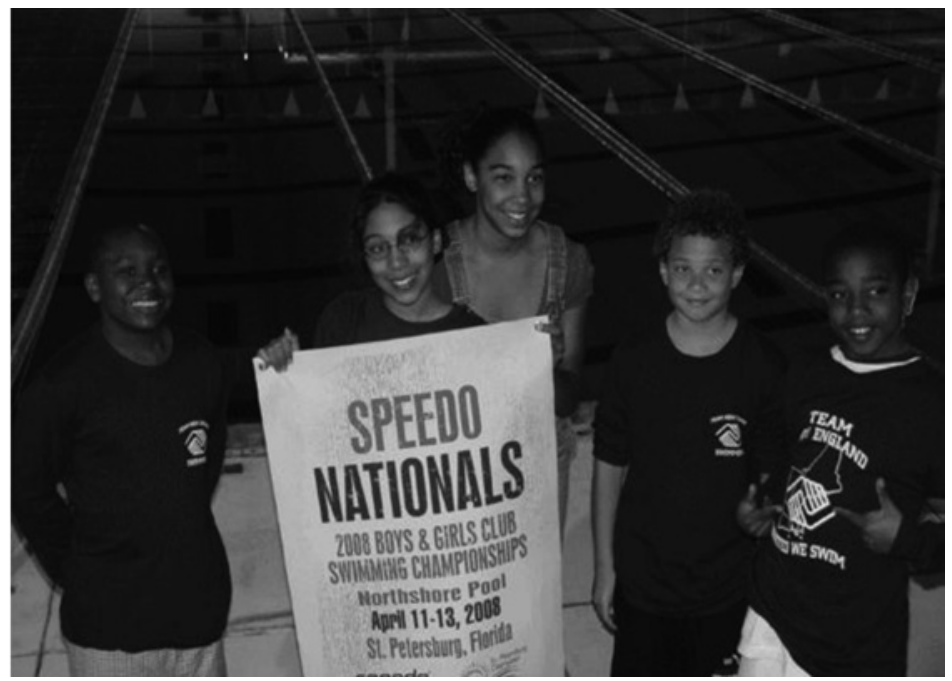

Yawkey Boys and Girls' Club (Boston, MA) Swim Team 2008 http://www.bgcb.org/cms/ images/swim-meet-1-lrg.gif

women's basketball. If we are truly concerned about diversity and inclusion in sport; we need to extend our research questions beyond a few "select" sports. The images we see in the photo from the 2008 Yawkey Boys and Girls' Club Swim Team could potentially be some of our next star student athletes and ultimately coaches or administrators. I just wanted to provide us with an opportunity to see some images of the young people who could potentially be some of our next star student-athletes. Moreover, because most—if not all—of my sport experiences as a participant, teacher and coach have been in the world of aquatic sports, my focus on diversity and inclusion in sport usually relates to the lesser known or visible sports of swimming, diving and synchronized swimming.

\section{Initial Reactions to Lapchick's Paper}

I appreciate the manner in which Dr. Lapchick organized his paper into two components: a) Hiring practices in intercollegiate sport and b) Gaps in graduation rates between African American and white student-athletes. I commend the work of Lapchick and his colleagues at the Institute for Diversity in Ethics and Sport during the past few decades. The reports (e.g., racial and gender report cards) have been a great resource for myself and countless other scholars and teachers. I realize the importance of focusing research and setting a context to explore issues of equity and inclusion where there are data to support the challenges and opportunities for increasing diversity and inclusion in intercollegiate sport. It is Lapchick's (2010) contention that the real power brokers in sport-the conference commissioners of the BCS schools - are the ones truly making the decisions that impact the diversity of coaches, administrators and presidents on those campuses. One very salient portion of Dr. Lapchick's paper was his discussion of the manner in which various 
forms of legislation and policy associated with that legislation can make inroads into facilitating social change and opportunity for people of color and women to move into coaching and administrative roles in intercollegiate sport. I agree with him and want to add the point that we not only need to change the manner in which people of color and women are recruited into these leadership roles; we also have to change the cultural climate in intercollegiate sport. If we continue to recruit more diverse people into these leadership roles but fail to change the social and cultural climate in intercollegiate sport, then "old" and long-lasting patterns of racism, sexism, heterosexism and homophobia will continue to manifest themselves in intercollegiate sport. In other words, not only do we need strategies for recruiting more people of color and women into leadership roles; we also have to work together and organize intercollegiate sport so that it is truly welcoming for and inviting to ALL people.

Quite honestly, I understand and agree with everything that Dr. Lapchick has discussed in his paper; so I won't restate all the excellent points and demographics that Dr. Lapchick addresses. However, I would like to see if we could extend the conversation to consider aspects of diversity beyond "black and white".

\section{Diversity and Inclusion Matter in Sport-Let's Take the Story Beyond Black and White}

Sport can provide sites where participants can derive positive social, psychological and physical benefits. There are numerous texts in the sport studies literature that describe these phenomena. Despite all the wonderful research and writing about the potential benefits for sport participation, we are still in a time in American society when we need reminders of these benefits as evidenced in the 2009 report from the WSF entitled "Her Life Depends on It" (Staurowsky, DeSousa, Ducher, Gentner, Miller, Shakib, Theberge, \& Williams, 2009). Most striking to me after reading that report was the statement related to girls of color.

Females from lower economic backgrounds and females of color engage less in physical activity, have less access to sport and physical fitness programs, and suffer negative health consequences as a result (p. 7).

Perhaps one of the reasons for such shortcomings in the promotion of sport and its benefits to poor girls of color is our inability as researchers, educators, and practitioners to consider the complex intersections among our various social and cultural identities. The intersections of race, ethnicity, gender, class are very complex. As Armstrong and O'Bryant (2007) noted, “....race/ethnic and gender ideologies often intersect to create and substantiate patterns of oppression and negative racial and gender discrimination that [can] adversely influence leadership experiences, opportunities and aspirations [for women of color]" (p. 271). This is why my first reaction after reading Dr. Lapchick's paper is that he, like most other authors, focuses his writing on the higher profile sports of basketball and football, thereby highlighting how the economic downturn impacts intercollegiate sport from a very limited perspective.

As Gill and Williams (2008) stated, "gender and cultural diversity are ever present and powerful in sport..." (p. 267). These authors continue by saying that "People cannot be separated from their gender and cultural context" (p. 267). I couldn't agree more [reflect back to my own background]. Perhaps the most fundamental catalyst for my reaction to Dr. Lapchick's paper comes from Douglas 
and Jamieson's (2006) assumption that the formations of race, class, sex, gender, and sexuality are interconnected and that it is inherently difficult if not impossible to explore the mutually exclusive experiences of one group of people (e.g., men or women) without considering the aforementioned intersections. In other words, there are multiple systems of oppression that shape the conditions in which we all live and experience sport (Collins, 1990 as cited in Douglas and Jamieson, 2006).

The complexity of the intersections among race, gender, gender identity, ethnicity, religion, class, disability and sexuality combined with what I consider to be the andocentric and Eurocentric study of sport in American society have indeed made it very difficult for sport studies scholars to ramp up their efforts to move beyond the experiences of African American men when researching "race" and move beyond White women when conducting research on gender or sexuality in sport. All that being said, a series of questions began to formulate in my mind as I read Dr. Lapchick's paper:

What do we know about visibility of and opportunities for:

- People in sports other than basketball and football?

- People with disabilities?

- The on-going impact of homophobia and heterosexism in intercollegiate sport?

It is beyond the scope of my reaction to Dr. Lapchick's paper to answer each of these questions in the short time I have on the podium, but it is important that I ask the questions because I feel they are important if we truly want to serve as advocates for diversity and inclusion in intercollegiate sport-especially at a time when there are shrinking fiscal resources due to the economic recession. What I can offer is a model that we could possibly use to help us move toward exploring diversity and inclusion in sport in terms of the intersectionality of social and cultural identities rather than focusing on those identities as separate and distinct from one another.

In 2004, Pat Griffin and I were planning for a workshop on diversity and transitioning AAHPERD from a monocultural to a multicultural organization. As we discussed the portion of the workshop related to helping participants develop an awareness of visibility and oppression within organizations; we thought that it would be important for each person to see how they are not "just" white or "just" male or "just" gay, etc. We are a combination of many overlapping and intersecting social and cultural identities.

Sometimes we experience social or cultural "privilege/advantage" because of one aspect of our identity and other times we experience negative discrimination/ discrimination/disadvantage due to another. I will use myself as an example. As a result of my educational $\mathrm{Ph}$. D. privilege, I have a chance to participate in this scholarly colloquium and can network with people who serve in a variety of leadership and "power" roles on my university campus or in organizations such as the NCAA. However, each day I am exposed to covert and overt displays of negative discrimination based on my skin color. As an African American person, I have had colleagues who have called my integrity and position into question. . . am I just here because of affirmative action or did I earn my spot in higher education like everyone else? Dr. Griffin and I used a visual model to help us explore this intersectionality of identity, power and privilege. We referred to it as a "Mosaic of Identity" (see image below). 


\section{Ethnicity}

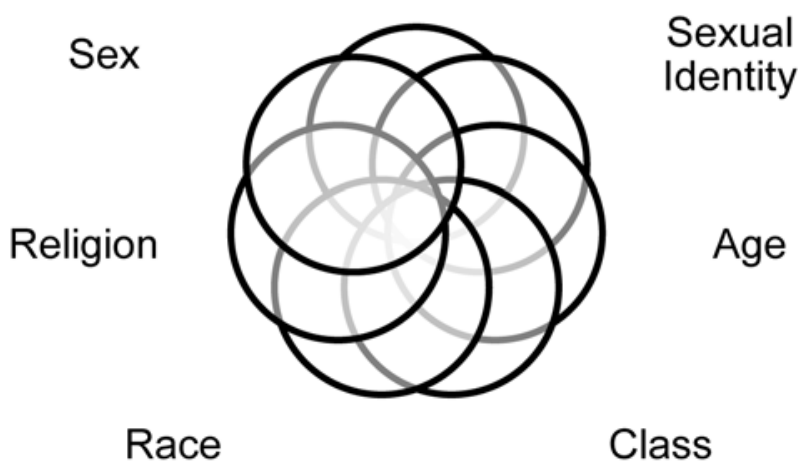

Mosaic of Identity

It is intriguing for me to observe students as they explore their own mosaics of identity and discuss with their peers how they move into, through and out of organized sport with different experiences based on a combination of race, ethnicity, gender, sexual orientation, etc.

This awareness is something that educators, policy makers and leaders in intercollegiate sport need to continue to develop if we stand a chance at socially constructing sport in a manner which is increasingly diverse and inclusive.

\section{Challenges to Diversity and Inclusion in Intercollegiate Sport-Beyond Football}

There are many areas of diversity and inclusion that warrant our attention in these tough economic times. Perhaps the most salient of these areas is the negative impacts of homophobia and heterosexism on women and men from all ethnic groups. Herek (as cited by Cunningham, 2007) stated that there is still negativity toward gay, lesbian, bisexual and transgender people. Cunningham (2007) cites Anderson, who said that [negative] sexual prejudice is especially prevalent among athletes on men's teams. Many homosexual coaches still choose not to self-identify as gay due in part to a concern that they a) may lose their jobs or b) be subject to harassment and many forms of covert and overt discrimination. Can someone please explain to me how a head coach of a Big 10 athletic team could lead her team with an openly antigay policy? Let's take a moment to watch a brief trailer from a new documentary entitled "Training Rules" to get a glimpse at how many athletes' intercollegiate sport experiences are cut short and/or negatively impacted (http://www.trainingrules.com/trailer.html).

In his paper, Lapchick underlines the importance of having key coaches and influential leaders in sport (e.g., Tony Dungy) take a visibly supportive role in promoting diversity and inclusion in sport. I think that we need similar models for athletes who are lesbian, gay, and transgendered as well as athletes with disabilities. 
Jeff Pearlmen (2009) addresses these issues in his blog about the Gay Athlete when he asks, why we need such role models

[Why?] Because right now, at this precise moment in 2009, there is a desperate need for leaders in the gay-rights movement; a desperate need for high-profile people to make a Rosa Parks-esque statement. Just last week, the California Supreme Court came to a jarringly narrow conclusion, voting to uphold Proposition 8, which limits marriage to only between heterosexual couples. The decision serves as Exhibit 1A on how far this country has to go when it comes to accepting gays and lesbians as equals. It also serves as Exhibit 1A on why you are being called to action. (http://jeffpearlman.com/?p=1791)

Personally, I am still waiting for a day when the leaders in the NCAA provide more voice and visibility to lesbian, gay, bisexual, and transgender coaches and administrators and their allies in a manner that not only celebrates the diversity and complexity of gender identity, gender expression, and sexual orientation but also consistently makes it clear that they will no longer stand by and allow the chronic and prolific homophobia and heterosexism that still occurs in member institutions.

Next, I want to bring our attention to student-athletes with disabilities. The disability sport movement has gradually gained visibility in sport at the high school and Olympic levels but, once again, the NCAA lags behind in providing meaningful and accessible participation opportunities for student athletes. There will no doubt be an increase in the demand for such sport opportunities on college campuses as men and women with disabilities call for reasonable and equitable sport participation opportunities. Lakowski (2009) draws our attention to the lack of opportunities for students with disabilities to compete in intercollegiate and interscholastic sports - referring to them as "...extremely limited". .....and adds that "The National Collegiate Athletic Association (NCAA) and the National Federation of State High School Associations (NFSHSA) do not officially sanction any intercollegiate or interscholastic program, event or competition for individuals with disabilities (p. 285). Lakowski provides a long list of examples where individual states have either mainstreamed students with disabilities into competitive teams or created adapted sports programs. Sadly I could not find a similar "list" of such opportunities when researching the NCAA web page and could not find any clear examples of what the NCAA is doing to facilitate sport participation for student athletes with disabilities.

\section{Possibility and Promise in the NCAA}

According to information on the NCAA web page, "Diversity and Inclusion is directly tied to the Association's core values and is linked with the NCAA Strategic Plan. More specifically, Diversity and Inclusion's efforts relate to the Association's core value of diversity, which urges member institutions, athletics conferences and governance groups to be committed to creating and supporting an inclusive culture that fosters equitable participation for student-athletes and career opportunities for coaches and administrators from diverse backgrounds." (http://www.ncaa.org/wps/ ncaa?key=/ncaa/ncaa/about+the+ncaa/diversity+and+inclusion, II 1) 
There is a very good video that I encourage everyone to watch. There a wide variety of people talking about how they define diversity and why it is important in their own words (http://web1.ncaa.org/web_video/diversity_inclusion/ diversityInAthletics.html). I found it very interesting to listen to different people talk about how they are defined. More importantly, when I watched the video, I saw the potential within the NCAA to open the door diversity and inclusion in a manner that goes beyond "black and white" and football.

Dr. Lapchick drew our attention to some of the successes that come from programs and initiatives such as the NCAA Football Coaches Academy and Achieving Coaching Excellence (ACE) Programs. These and other programs, including but not limited to, Matching Grants for Women Coaches, Division II Coaching Enhancement Grant and those in athletics administration such as: NCAA Fellows Leadership Development Program, Leadership Institute for Ethnic Minority Males and Females, Division II Strategic Alliance Matching Grant Enhancement Program and Division III Strategic Alliance Matching Grant take time, and fiscal as well as human resources to sustain. They are a great beginning, but without continued support-fiscal and logistical-we may not be able to move our understanding of and commitment to diversity and inclusion beyond "black and white" or football.

It is my contention that researchers and administrators need to demonstrate to people that there's more to diversity and inclusion than race and gender and that football and men's basketball are not the only NCAA sports that are negatively impacted by the economic recession. The NCAA has created some excellent materials and programs for the education about and management of diversity and inclusion in [intercollegiate] sport. I hope that leaders in the NCAA continue to modify and update those programs in a manner that embraces intersectionality of race/ethnicity, gender, sexuality, gender identity, disability and class in those programs. I also look forward to more research and writing in intercollegiate sport that moves us [FBS] football and Division I men's basketball. Of course these take fiscal and human resources and the current state of our nation's economy creates challenges about how to allocate those resources. The programs that the NCAA has in place to help develop diversity and inclusion appear to be working, at least as evidenced in the examples that Dr. Lapchick provides in his paper. I hope they continue to receive the support and funding that are necessary to provide opportunities for a wider variety of aspiring coaches and administrators. My concern is that the current economic downturn has created an environment where the focus on FBS schools and men's basketball is pushing the needs, concerns, voices and visibilities of the vast majority of athletes deeper into the margins of intercollegiate sport than they have ever been.

\section{References}

Armstrong, K., \& O’Bryant, C. (2007). Women of color. In M.A. Hums, G.G. Bower, \& H. Grappendorf (Eds.), Women as Leaders in Sport: Impact and Influence (pp. 269-298). Oxon Hill, MD: AAHPERD Publications.

Cunningham, G.B. (2007). Diversity in Sport Organizations. Scottsdale, AZ: Holcomb Hathaway. 
Douglas, D., \& Jamieson, K. (2006). A Farewell to Remember: Interrogating the Nancy Lopez Farewell Tour. Sociology of Sport Journal, 23(2), 117-141 Retrieved from SPORTDiscus with Full Text database.

Gill, D., Jamieson, K., Kamphoff, C., Scrogum, J., \& Fuse, T. (2006). Physical Activity Professionals' and Preprofessionals' Perceptions of Multicultural Competence. (Abstract). Research Quarterly for Exercise and Sport, 77(1, Suppl) A-77 Retrieved from SPORTDiscus with Full Text database.

Gill, D.L., \& Williams, L. (2008). Psychological Dynamics of Sport and Exercise (3rd ed.). Champaign, IL: Human Kinetics.

Jamieson, K. (2003). Occupying a Middle Space: Toward A Mestiza Sport Studies. Sociology of Sport Journal, 20(1), 1-16 Retrieved from SPORTDiscus with Full Text database.

Lapchick, R. (2010). The Effect of Economic Downturn on College Athletics and Athletic Departments on Issues of Diversity and Inclusion, Journal of Intercollegiate Sport, $3,81-95$.

Lakowski, T. (2009). Athletes with disabilities in school sport: A critical assessment of the state of sports opportunities for students with disabilities. Boston University International Law Journal. 27 pp. 283-315 Retrieved January 2010 from www.bu.edu/law/ central/jd/organizations/journals/.../5Lakowski.pdf.

National Collegiate Athletic Association. (2007). 2005-2006 Ethnicity and Gender Demographics of NCAA Member Institutions' Athletic Personnel: The NCAA Minority Opportunities and Interests Committee's Biennial Study. Retrieved January 3, 2010 from http://www.ncaapublications.com/Uploads/PDF/2005-06_ethnicity_gender_ demographics10e49b7e-09c8-434c-8f97-e4cf9a22a46b.pdf.

Pearlmen, J. (2009, June). The Gay Athlete. Retrieved December 22, 2009 from http:// jeffpearlman.com/?p=1791.

Staurowsky, E.J., DeSousa, M.J., Ducher, G., Gentner, N., Miller, K.E., Shakib, S., et al. (2009). Her Life Depends On It II: Sport, Physical Activity, and the Health and WellBeing of American Girls and Women. East Meadow, NY: Women's Sports Foundation. 